\title{
Forthcoming meetings convened by the Conference of European Statiscians
}

1. Seminar on the role and functions of statistical services within the overall information system of a country (Paris, September 1986).

The seminar is intended for executive officials of national statistical services. It will be held in Paris at the invitation of the Government of France. The participants will discuss questions such as cooperation between national administrations in the generation of statistics, functions of national statistical services in a diversified information system, technical links between information systems, and the effects of integrated information systems on the relations between data users and statistical offices.

2. Meeting on statistics of households and families (Geneva, September 1986)

This meeting will focus on census aspects of statistics of households and families. The participants will review the definitions and classifications of households and families contained in the Recommendations for the 1980 Censuses of Population and Housing in the ECE Region, consider the criteria used in applying these definitions in different data sources and particularly in population and housing censuses, and exchange experiences on the usage of automated coding for household and family statistics.

3. Seventeenth session of the Study Group on Food and Agricultural Statistics in Europe (Geneva, July 1986)

The session was announced previously for May 1986. It is postponed to July of the same year. 